\title{
Report of the 2015 Malawi trachoma mass drug administration (mda) coverage survey in 9 districts
}

\begin{abstract}
For Mass Drug administration(MDA), whereas it is recommended that at-least $85 \%$ coverage in a district is the optimal figure that needs to be reached for an MDA to be consider successful, standard trachoma drug coverage surveys only require $80 \%$, as the cut off line to determine whether MDA was adequately done. ${ }^{1}$ Coverage surveys were conducted between November and December 2015 in 9 of the 13 districts (Nsanje, Zomba, Machinga, Mwanza, Neno, Ntcheu, Lilongwe East, Dowa and Ntchisi) that implemented MDA in 2015.Surveys were not conducted in Kasungu, Nkhotakota, Salima and Lilongwe West. The results indicate that 6 out of the 9 districts (Nsanje, Zomba, Mwanza, Neno, Ntcheu and Lilongwe east) had achieved the required coverage of at least $80 \%$ during the MDA. ${ }^{2}$ Four districts (Machinga, Dowa and Ntchis and Nsanje) failed to reach the desired coverage. It may be argued that Nsanje reached this, as the percentage was $79.8 \%$ and was rounded up to $80 \%$. The Main reason for low coverage was attributed to delayed drug distribution, wrong population projections, shortage of in-country supplies of Zithromax, and maldistribution of Zithromax within districts.
\end{abstract}

Volume 6 Issue I - 2017

\author{
Kalua Khumbo, Balakasi Salomie, Chisambi \\ Alvin, Masika Micheal, Kanjado Thomas, \\ Singano Ranneck, Moyo George \\ Lions Sight First Eye Hospital, Malawi
}

Correspondence: Moyo George, Blantyre Institute for Community Outreach, Lions Sight First Eye Hospital, PO Box EI80, Post Dot Net Blantyre, Malawi,

Tel +265I875377, +265999958I76,

Email george@bicomalawi.org

Received: December 09, 2016 | Published: January 20, 2017
Abbreviations: MDA, mass drug administration; ITI, international trachoma initiative; BICO, blantyre institute for community ophthalmology; $\mathrm{MOH}$, ministry of health; $\mathrm{HH}$, households; NSO, national statistical office

\section{Introduction}

International Trachoma Initiative (ITI) in 2014 approved one round of MDA for 8 districts in Malawi who had a Trachoma TF prevalence of between $5.0 \& 9.9 \%$; and lessons from this approach will be useful for decision making for other countries which have districts that fall in this category. The MDA took place between October and November 2015 in all the districts. Blantyre Institute for Community Ophthalmology (BICO) conducted coverage surveys in these 8 districts from 10th November to 18th December 2015, done at least two weeks after MOH declared the 2015 MDA exercise over and reported its coverage's. The surveys took place in Zomba, Machinga, Ntcheu, Mwanza, Neno, Ntchisi, Lilongwe West ad Dowa districts which all had a TF prevalence of between 5.0 and $9.9 \%$ and needed one round of MDA. Under this arrangement, it is desirable that districts achieve a higher coverage of at least $80 \%$. Nsanje was added even though it was implementing MDA for the third year.

\section{Objectives of the coverage survey}

The main objective of the survey to determine the drug coverage in all the districts that were covered and compare this with the Ministry of Health (MOH) official figures, Specifically the survey was conducted to:

i. To establish the geographical coverage during the MDA

ii. To establish the therapeutic MDA coverage

iii. To determine reasons for the achieved coverage.
In terms of procedure the survey was meant to:

I. Find out if individuals really took the drugs

II. Find out the reasons why others did not take the drugs

III. Document the side effects that some had after taking the drug

\section{Methodology}

The individual activities involved in the methodology were as follows:

I. Generate a list of all villages (clusters) within a district

II. Randomly select 30 clusters (village) per districts

III. Send a team with questionnaires to intervene households $(\mathrm{HH})$

IV. Team selects 7-10 households per village and interview everyone in the $\mathrm{HH}$

V. Team uses Mhealth (android smart phone) to send data to a server

VI. Data analyses

VII. Reporting

\section{Sampling}

The survey that was conducted using the standard 30 by 7 methodology for coverage surveys, and the compact segment sampling 30 clusters (villages) were sampled randomly in each of the 8 districts. The clusters were then segmented depending on the number of households in a cluster. The segments were made in such a way that there were at least 50 households in each segment which would allow at least 7 households being surveyed in a segment. In each cluster a single segment was surveyed with a house ratio of 1:7. ${ }^{3}$ 


\section{Data collection}

Data was collected using android phones with an android application called links. An electronic questionnaire was downloaded on to the phones from the links server and that questionnaire was used for data collection by the recorders in the field. Data was uploaded on to the server on daily basis as soon as the recorders are back from field. ${ }^{4}$

\section{Training and field work}

The survey started with training of the recorders which took place on 21st-24th November, 2015 in Blantyre at the conference room and in Mwanza for field practice. Trainers were Dr Khumbo kalua, Director BICO, assisted by Alvin Chisambi and Salomie Balakasi (BICO ICT trainers). There were seven enumerators and two supervisors (see attached list) throughout the survey period. Classroom training took one whole day and this was followed up field work practice in one district (Mwanza) the next day. After successful field work, actual data took place between 24th November to 18th December 2015. The basic information contained in the electronic questionnaire had the following information.

I. Did you know about the MDA exercise?

II. Did you take the drug?

III. Which drug? How much?

IV. Were they any side effects?

V. If not, Why did you not take the drug

District overage was calculated as total number of those who took the drugs from the 30 clusters divided by the total number interviewed. The randomness of selection of clusters gave the confidence to generalise results to the entire district. ${ }^{3}$

\section{Clusters and cluster ids}

There were 30 clusters in each of the 8 districts. That made a total of 240 clusters and therefore the cluster IDS were numbered for first one as 102,102 etc.

\section{Results}

The names of the trainers, supervisors and recorders who took part in the COVERAGE survey are shown in Table 1. An MOH representative and a Sight savers representative was available as supervisors throughout the survey period. The detailed list of all the selected clusters per district and the participants that were interviewed per each clusters are shown in the csv file (attached separately). The number of residents interviewed per district and the drug coverage is shown in Table 2. *For Nsanje reached this, as the percentage was $79.8 \%$, it was rounded up to $80 \%$. As can be seen from table 2,6 out of the 9 districts (with Nsanje added) reached a coverage survey of $80 \%$, indicating that MDA was adequately done in those districts. ${ }^{3}$ Only Machinga, Dowa and Ntchisi did not achieve this. Machinga had the lowest coverage of $69.5 \%$ and this was attributed to drug shortage within the district. The main reason why people did not take the medicines was that they were either away on the day of the MDA or that there were told by health workers that medicines had run out. In some circumstances where the drugs were available, action was taken after the coverage survey to mop up the districts so that those who did not take the drug had the chance to do so (see specific examples under session "interesting observations").
Table I Coverage survey teams

\begin{tabular}{ll}
\hline Trainers & Khumbo kalua \\
& Alvin chisambi \\
& Salomie balakasi \\
Supervisors & Alvin chisambi \\
& Michale masika (Moh) \\
& Thomas kanjado (Sightsavers) \\
& Alvin chisambi \\
& Salomie balakasi \\
& Ranneck singano \\
Enumerators (Recorders) & Madalitso jamali \\
Geofffrey mandalennox gondwe \\
Hlupekile shawa \\
Lesley mulaga \\
Francis ligomeka \\
Hisungatha
\end{tabular}

Table 2 Drug coverage

\begin{tabular}{llll}
\hline & No. interviewed & No.took drugs & $\begin{array}{l}\text { Drug coverage } \\
\text { (therapeutic)\% }\end{array}$ \\
\hline Nsanje & 1114 & 889 & $\begin{array}{l}79.8 \% * \text { (Rounded } \\
\text { to } 80 \%)\end{array}$ \\
Machinga & 1180 & 820 & $72.10 \%$ \\
Dowa & 1129 & 814 & $81.50 \%$ \\
Ntcheu & 1024 & 856 & $69.50 \%$ \\
Zomba & 1024 & 835 & $83.60 \%$ \\
Mwanza & 1087 & 904 & $83.20 \%$ \\
Neno & 1134 & 928 & $81.80 \%$ \\
Ntchisi & 1100 & 820 & $74.50 \%$ \\
Lilongwe & 1103 & 925 & $83.90 \%$ \\
W & & &
\end{tabular}

In-terms of geographical coverage, we established that except for a few villages, the medicine was distributed throughout the entire districts (so coverage was 100\%). However, the quantities needed given to each village was not calculated based on the village population and the number of tablets or syrup needed, partly because the officers given the responsibility could not figure out how and where to allocate the $5 \%$ shortage (as only $95 \%$ of the required was given). This resulted in other areas (mainly areas farthest from the district hospital headquarters) getting more than was needed while areas near district hospital had short supplies. It was not easy to determine where the excess drug was.

Table 3 compares the survey district drug coverage obtained with official results reported by Ministry of Health $(\mathrm{MOH})$ using the 
National statistical office (NSO) and in some cases the actual head count (village census before the MDA). Coverage survey results were lower than official MOH figures (either by NSO or headcount) but correlated well in the following districts: Zomba, Ntchisi and Lilongwe West. Overall coverage survey results were closer to

Table 3 Therapeutic Drug coverage survey results compared to $\mathrm{MOH}$ figures coverage's obtained when using district head count (actual village census) than when using National statistical office (NSO) projection figures. Using the NSO, only Ntchisi and Lilongwe West did not reach $85 \%$ coverage.

\begin{tabular}{|c|c|c|c|c|c|c|c|c|}
\hline & District & $\begin{array}{l}\text { NSO' } \\
(2015)\end{array}$ & $\begin{array}{l}\text { Head count } \\
\text { figures }^{2}\end{array}$ & $\begin{array}{l}\text { Total } \\
\text { treated }\end{array}$ & $\begin{array}{l}\text { MOH coverage by } \\
\text { NSO }\end{array}$ & $\begin{array}{l}\text { Coverage by head } \\
\text { count }\end{array}$ & $\begin{array}{l}\text { Coverage by } \\
\text { survey }\end{array}$ & Successful \\
\hline I & Nsanje & 291953 & 320,945 & 302,623 & $104 \%$ & $94.3 \%$ & $79.8 \%$ & Yes \\
\hline 2 & Dowa & 649,139 & 679,448 & 592,207 & $91 \%$ & $87.20 \%$ & $72.1 \%$ & No \\
\hline 3 & Zomba & 340,014 & 394,813 & 322,973 & $95 \%$ & $81.80 \%$ & $81.5 \%$ & Yes \\
\hline 4 & Machinga & 570,215 & 664,250 & 529,227 & $93 \%$ & $79.70 \%$ & $69.5 \%$ & No \\
\hline 5 & Ntcheu & 552,269 & 589,940 & 510,713 & $92 \%$ & $86.60 \%$ & $83.6 \%$ & Yes \\
\hline 6 & Mwanza & 110,168 & $?$ & 102,456 & $93 \%$ & $?$ & $83.2 \%$ & Yes \\
\hline 7 & Neno & 126,984 & $?$ & 114,286 & $90 \%$ & $?$ & $81.8 \%$ & Yes \\
\hline 8 & Ntchisi & 261,319 & $?$ & 209,055 & $80 \%$ & $?$ & $74.5 \%$ & No \\
\hline 9 & Lilongwe West & 770,850 & ? & 632,097 & $82 \%$ & $?$ & $83.9 \%$ & Yes \\
\hline
\end{tabular}

'NSO-National Statistical Office

${ }^{2}$ figures obtained from actual household count prior to MDA

From this table, one can conclude that the total population obtained by head count was slightly higher than the population using the NSO, such that the medicine that came were indeed less than what was needed to treat the entire population. This was even compounded by the fact that only $95 \%$ of the required Zithromax was sent, and that staff did not know how to ration this to cover the entire district. The result is that all districts complained that there was a severe shortage of Zithromax. However, it was later established that shortage was more of a result of maldistribution rather than the actual shortage. Some health centres and villages got more than they needed, while others had less. it was difficult to know who had more or less until the MDA exercise was completed and drug collection was done. It was at this point that it was discovered that actually there were drugs that were left overs and these were sent back to the needed areas. In the case of Machinga (which has the lowest coverage), after the coverage survey, left over drugs were mobilised from all over the country and sent back to Machinga for redistribution.

\section{Interesting observations}

The issue of drug shortage, compounded by maldistribution, affected the drug coverage in some of the villages. The district pharmacists received some medicines at the district hospitals, and only distributed a few to the health centres. They informed health centre staff that if they ran out of medicines they should order more. Priority was only given to areas which were farthest from the districts as these got more medicines than needed. There was panic that not enough drugs were sent, and this created a false high demand which resulted in very long queues during the first day. The drugs given to health workers ran out within the first two days and this left some villages completely with not even a single person receiving the drug.

We established that in Machinga, Zomba, Dowa, Ntchisi, Mwanza districts some selected villages did not receive any medicines for distribution. We also established that in all districts, a proportion of villages received only half of what was required in the first instance, and then later received the remaining drugs during the mop up period. MDA exercise took longer than the prescribe one-week period to finish in some villages, as drugs had to be sourced from elsewhere after the mop up. In some circumstances the period extended to more than one month. After the coverage surveys, all surrounding areas that reported to have had a low coverage were investigated, and if the drug was available this was redistributed. We established that by the end of the coverage survey, there was very little in-country left over's of MDA drugs.

\section{Conclusion}

The coverage survey showed that Malawi did not achieve a minimum of $80 \%$ coverage in 3 districts, and resulted in further mop up activities in two of these (Dowa and Machinga) to achieve this. However, this was not completely possible due to shortage of the drugs, which completely run out. Coverage survey was useful in highlighting 2015 MDA challenges in Malawi, and in explaining differences in coverage's reported by $\mathrm{MOH}$. The main reason why the country had a challenge was as a result of receiving only $95 \%$ of the approved drug, based on NSO figures, yet the actual head count was higher than NSO projected figures. Receipt of less than excepted drug and the delay in receiving the drugs caused in-country panic leading to wrong maldistribution of drugs. Despite this confusion, overall no district achieved less than $80 \%$ according to NSO figures, and Malawi need to be recommended for this. The fact that head count was higher than NSO raises questions as to how accurate it is to order drugs based on NSO and not based on the actual count.

\section{Recommendations}

Malawi needs to receive $100 \%$ of the approved drug to avoid incountry confusion about how the drug should be distributed. Impact surveys should be conducted as soon as possible to establish if districts may need another round of MDA in 2016. 


\section{Funding}

None.

\section{Acknowledgments}

None.

\section{Conflicts of interest}

The authors declare that there was no conflict of interest.

\section{References}

1. Cromwell EA, King JD, McPherson S, et al. Monitoring of mass distribution interventions for trachoma in Plateau State, Nigeria. PLoS Negl Trop Dis. 2013;7(1).
2. Harding-Esch EM, Sillah A, Edwards T, et al. Mass treatment with azithromycin for trachoma: when is one round enough? Results from the PRET Trial in the Gambia. PLoS Negl Trop Dis. 2013;7(6):e2115.

3. Worrell C, Mathieu E. Drug coverage surveys for neglected tropical diseases: 10 years of field experience. Am J Trop Med Hyg. 2012;87(2):216-222.

4. Won-Jae Yi, Weidi Jia, Jafar Saniie. Mobile sensor data collector using Android smartphone. In: 2012 IEEE 55th International Midwest Symposium on Circuits and Systems. IEEE; 2012. p. 956-959. 